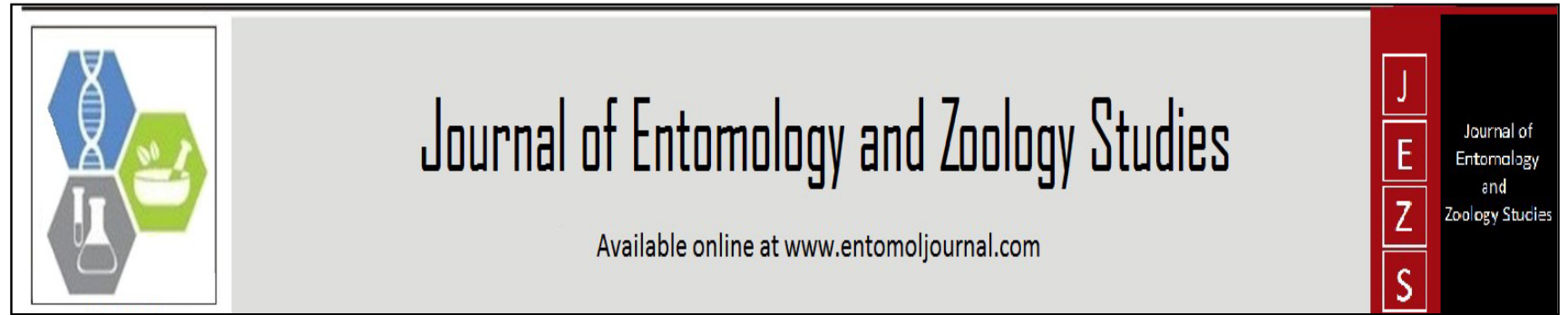

E-ISSN: 2320-7078 P-ISSN: 2349-6800 JEZS 2015; 3(4): 77-78

(C) 2015 JEZS

Received: 02-06-2015

Accepted: 04-07-2015

Mark Ian Cooper

Department of Biological Sciences, University of Cape Town, Republic of South Africa.
Correspondence:

Mark Ian Cooper

Department of Biological

Sciences, University of Cape

Town, Republic of South Africa.

\section{Competition affected by re-mating interval in a myriapod}

\section{Mark Ian Cooper}

\section{Abstract}

Copulation duration, re-mating interval, and ejaculate volume (disintegrations per minute of $\mathrm{H}^{3+}$ ) was analyzed in the millipede Chersastus inscriptus. Re-mating interval negatively related to second duration $(y=36+0.01 x)$ and relative ejaculate volume increased from $21 \%$ to $77 \%$ in favor of second males after 24h intervals.

Keywords: arthropod, copulation, diplopod, invertebrate, pachybolid, spirobolid

\section{Introduction}

In millipedes, copulation duration is known from some African ${ }^{[1-7]}$, Australian ${ }^{[8]}$ and American species [9], however few studies investigate sperm or ejaculate precedence [1]. Second male sperm precedence correlates with prolonged second copulation duration and can be analyzed from sperm volumes ${ }^{[1,7]}$. Ejaculate volume precedence of males was analyzed in double mating experiments with 24 hour (h) re-mating intervals in Chersastus inscriptus.

\section{Materials and methods}

Chersastus inscriptus were collected from Twin Streams (2855'S, $\left.31^{\circ} 45^{\prime} \mathrm{E}\right)$ (1995 - 1998). Live specimens of each sex were taken to a laboratory, kept at $25^{\circ} \mathrm{C} ; 70 \%$ relative humidity; 12:12 h light-dark. Vegetables were provided ad lib. Unisex groups were kept in plastic containers lined by moist vermiculite $( \pm 5 \mathrm{~cm}$ deep). Ejaculate volume was measured as disintegrations per minute (dpm) tritium in a 1600 scintillation counter (low count reject $=0$; dpm multiplier $=1$ ). Millipedes were marked on posterior segments with colored tipex and placed in glass aquaria (30 X $22 \times 22 \mathrm{~mm}$ ). Pairs were isolated in plastic beakers $(13 \mathrm{~cm}$ diameter) and mating timed. Double mating sequences were performed to test for order or interval effect. Mating order was controlled by mating females with labelled and un-labelled males in reciprocity. Females were given the opportunity for second mating immediately (0-h delay) or later (24-h delay). As controls, females that had single mating with labelled males were dissected immediately or $24 \mathrm{~h}$ later. Females that had single mating with unlabeled males were dissected to control for background radiation. Data were analyzed with Pearson's correlation (r), t-tests (t), Spearman's rank order correlation coefficients (r), two-tailed MannWhitney U-tests (Z), and Wilcoxon tests (T). A Kruskal Wallis 1-way ANOVA (H) was used to test for differences in dpm data prior to Mann-Whitney U-tests.

\section{Results}

Copulation duration in $C$. inscriptus lasted $173 \pm 41$ minutes. First duration (174 \pm 35 min.) and second duration $(173 \pm 47 \mathrm{~min}$.) were the same $(\mathrm{T}=507, \mathrm{n}=46, \mathrm{P}=0.91)$ and were not correlated $(\mathrm{r}=-0.06, \mathrm{n}=46, \mathrm{P}=0.69)$. The interval was not related to first duration $(\mathrm{r}=0.07, \mathrm{n}$ $=46, \mathrm{P}=0.64)$ but was negatively related to second duration $(\mathrm{r}=-0.31, \mathrm{n}=46, \mathrm{P}=0.04) ; y=$ $36+0.01 x$. Differences in successive copulations were present $(\mathrm{r}=0.33, \mathrm{n}=46, \mathrm{P}<0.05)$. No differences between duration of isotope-labelled and unlabeled males $(\mathrm{t}=0.38$, d. f. $=28, \mathrm{P}=$ $0.70)$, or between left and right vulvae of females ( $T=711.5, \mathrm{n}=59, \mathrm{P}=0.19)$ occurred. Overall differences were found in total dpm $(\mathrm{H}=30.67$, d. $\mathrm{f} .=5, \mathrm{P}=0.00001)$. Immediate impact of the second male on the first male was absent $(Z=0.84, n=6,12, P=0.40)$. The dpm of the first male was higher than the second male $(Z=3.37, n=6,12, P=0.0007)$ but with a delay of up to 24 h precedence reversed and second male's was higher $(Z=-2.59, n=8$, $14, \mathrm{P}=0.01$ ). There was no difference in dpm between single and double mating with 
controlled intervals $(\mathrm{Z}=0.58, \mathrm{n}=7.8, \mathrm{P}=0.56)$. There was a drop in dpm post-mating ( $\mathrm{Z}=3.00, \mathrm{n}=6,7, \mathrm{P}=0.003)$. Ejaculate displacement negatively related to copulation durations after $24 \mathrm{~h}(\mathrm{r}=-0.88, \mathrm{P}=0.004, \mathrm{n}=8)$ but not when females mated immediately $(r=-0.10, P=0.75, n=12)$.

\section{Discussion}

This study successfully uses a hypothetico-deductive approach to unravel three major factors (re-mating interval, mating duration, ejaculate volume) important to mate competition in a spirobolid millipede. Ejaculate volume (dpm) in C. inscriptus is a function of re-mating, rising from $21 \%$ to $77 \%$, in favor of second males after $24 \mathrm{~h}$. This is only the second case of female control of ejaculate in millipedes ${ }^{[1]}$. The ejaculate may equate with the female storage capacity. An untested assumption is ejaculate precedence equates with second male sperm precedence at the molecular level. Future research should investigate the effect of third males on mate guarding, and natural re-mating interval.

\section{References}

1. Barnett M, Telford SR, Tibbles BJ. Female mediation of sperm competition in the millipede Alloporus uncinatus (Diplopoda: Spirostreptidae). Behavioural Ecology \& Sociobiology 1995; 36:413-419.

2. Telford SR, Dangerfield JM. Sex in millipedes: laboratory studies on sexual selection. Journal of Biological Education 1990; 24:233-238.

3. Telford SR, Dangerfield JM. Manipulation of the sex-ratio and duration of copulation in the tropical millipede Alloporus uncinatus - a test of the copulatory guarding hypothesis. Animal Behaviour 1990; 40:984-986.

4. Telford SR, Dangerfield JM. Mating tactics in the tropical millipede Alloporus uncinatus (Diplopoda: Spirostreptidae). Behaviour 1993; 124:45-56.

5. Telford SR, Dangerfield JM. Males control the duration of copulation in the tropical millipede Alloporus uncinatus (Diplopoda: Julida). South African Journal of Zoology. 1994; 29:266-8.

6. Telford SR, Dangerfield JM. Sexual Selection in Savanna Millipedes: Products, Patterns and Processes. In: Geoffroy, J. J., Mauries, J.P. \& Nguyen Duy-Jacquemin, Mémoires du Muséum National d'Histoire Naturelle 1996; 169:565-576.

7. Cooper MI, Telford SR. Copulatory Sequences and Sexual Struggles in Millipedes. Journal of Insect Behaviour 2000; 13:217-230.

8. Rowe M. Copulation, mating system and sexual dimorphism in an Australian millipede, Cladethosoma clarum. Australian Journal of Zoology 2010; 58:127-132.

9. Mathews PL, Bultman TL. Mating behavior of a parajulid millipede, Aniulus bollmani. Canadian Journal of Zoology. 1993; 71:2297-2300. 